\title{
The Significance of Narratology in Teaching of Literary Works
}

\section{Wang Zhenzhen}

Humanities Branch of Yili normal University, Xinjiang, China, 100020

Keywords: narratology; literary works; teaching

\begin{abstract}
If the literary charm lies in the ability to understand and experience life in a unique artistic way, with novel and unique expression methods and innovative creations, the feeling of dullness to things will be renewed to show things that cannot be seen, and the charm of narratology lies in its superb ability to read "literary charm". It helps us understand how those "invisible things" are seen by us. Introducing the narratology theory into the field of literary works teaching in middle schools requires a relatively complicated working procedure. No matter how complicated this process is, the target must be Chinese classroom teaching, and it must inevitably involve teaching methods, which are analyzed in this paper.
\end{abstract}

\section{Introduction}

Narratology involves concepts such as narrators, narrative perspectives, narrative time, narrative structure, narrative types, and discourse patterns. These concepts represent the differences between them, different narrators, narrative perspectives, narrative time, narrative structure, and narrative. Types and discourse patterns necessarily have different narrative effects. The best way to reveal different places is to compare and contrast. No matter what specific teaching methods are adopted, comparisons will inevitably contain elements in them. There are many ways to compare, we can roughly divide it into three categories: the comparison between A text and B text, the comparison of the presentation of the text with another possibility, and the comparison within the text.

\section{Text Comparison}

For example, when Guo Chuanyang's teacher taught the 'Necklace' 2 lesson to guide students to interpret text themes, a blank-filling question was designed: This is a novel about students who fill in different content according to their own understanding, mainly including vanity and integrity. There are five categories: poverty, disparity, dreams, desires, and fate. Instead of simply affirming or denying the students' opinions, Teacher Guo explored them with the students, and finally passed the 'Necklace' and 'Cinderella' plot elements, and the characters in the two texts, Cinderella and Mathilde's In comparison, everyone unanimously discovered that the subject originally hidden in the text is a sigh of fate. Isn't it? In the comparison, we can see that Cinderella and Matilde's situation are strikingly similar, but the ending is very different. Vanity, honesty, poverty, disparity, dreams, and desires cannot explain their different outcomes. Only fate can explain. This method of comparison by Guo Chuyang is a comparison between the first A text and the B text. This comparison method is to put the text in an open background to explore its meaning [1]. The formula for narrative expression is as follows.

$$
p(k)=f(k) / \sum_{i=1}^{N-1} f(i)
$$

The teaching of 'Due Shi Niang's anger sinking treasure box' taught by Hugang High School in Huzhou, Zhejiang is a comparison of the presentation of the text and another possibility. Yang Gang and the students revised together to discuss the outline of what they wrote for the text. The teacher proposed that there is another content that needs to be added. The student should realize that he should 'make public the treasure box at the time of the official transaction' and should add a sentence: 'Original, the jewellery in the box is actually a private savings of Shi Niang's wind and 
dust for several years, worth two thousand yuan.' This will be able to clasp the problem. Next, the teacher told the students: 'It should be noted that according to the author's narrative, the narrator does not grasp the specific circumstances and mentality of Du Shi Niang's daily secret accumulation of the Treasure Box, and the reader can only pass through her when Du Shi Niang eventually jumps over the river. The complaint informed that she also had a treasure chest. This narrative was attributed to the 'out-of-focus narrative mode.' The teacher then took out his own written outline and asked the students to see if there was a difference in the narrative mode. The students realized that the narrative used in the text was in line with the actual story, but the author did not explicitly say that the reader could think of it. The teacher is in a position to tell the students that this is called the 'full focus narrative mode.' In this lesson, the teacher will The comparison between the narrative style and the other ones that did not appear in the comparison made the students appreciate the superiority of the text art technique [2].

\section{Character Experience}

The emergence of narratological theory is to open up a new aesthetic perspective for literary creation and literary reading. It not only enables us to read literary works more rationally, but also gives us a new perspective to review and regain an unusual experience. Especially for narrative methods, its ingenuity can only get real feelings by immersing itself in deep experience. Therefore, when using narratological theory to teach literary works, if we can't guide students to perform role experience, it is actually making this useless. When the theory of narratology is used in the teaching of literary works, we need to guide students in the role experience including two aspects: one is to experience the inner feelings of the characters in the context of text, and the other is to use the eyes of characters to experience the external world in which characters are exposed.

We see Yu Yingchao's teacher teaching 'If life deceives you' when telling students to read this poem can use the 'comfortable' and 'monologue' methods of reading. He told everyone that this poem is a few inscriptions that the poet wrote to the children of his neighbors under the most difficult circumstances during the exile. Then this poem has the meaning of comforting others and can be read in a manner of speaking. Because it is reasonable, it is talking. Then Yu taught the students to try another way of reading: 'When we encounter difficulties, when we encounter setbacks, when we feel that our shoulders cannot bear the burden of life, we tend to Clenching your fists to encourage yourself, this time there is a kind of inner monologue, quietly and encouraging yourself, then this inner monologue method is used for poetry recitation, suitable for listening to yourself, encouraging yourself and encouraging yourself.... This kind of 'shasha' The sound of reading will surely agitate our feelings.' In this period of factual recordings, Yu's teacher guided students to read this poem using 'comfortable style' and 'monologue style' to read. From the classroom form, it is The teacher guides the students to get close to the speech works and guides the students to try to change the 'reading' of the listening object [3].

Of course, there is no absolute demarcation between guiding the students to experience the inner feelings of the characters in the context of the text and guiding the students to use the eyes of the characters to experience the external world in which the characters are immersed. Only the emphasis is different, because the inner world is different. Feeling is the experience of the outside world. The feeling of the outside world is also due to the experience of the inner world.

\section{Provide Inter-textual Text}

The concept of "intertextuality" (also known as "intertextuality" or "intertextuality") was first described by French semiotician and feminist critic Julia Kristeva in her book Semiotics. Proposed: "The texts of any works are constructed like many mosaics. Any text is the absorption and transformation of other texts." 8 The basic connotation is that each text is a mirror of other texts, and each text is It is the absorption and transformation of other texts. They refer to each other and are involved with each other to form an open network with unlimited potential. This constitutes the evolutionary process of the text's past, present, and future huge open systems and literary semiotics. 
Therefore, interpreting a literary work is inseparable from the help provided by other texts associated with it, as Bloom said: 'In order to explain a poem, you must explain the difference between it and other poems. It is the place where the poem's freshness creates meaning." 9 In Broome's view, the meaning of text depends on the intertextuality, just as the meaning of a single sign depends on the division of meaning of the sign system, and the meaning of a single text exists. In teaching, students should be provided with some necessary intertextual texts[4].Intertextual text structure diagram is as follows.

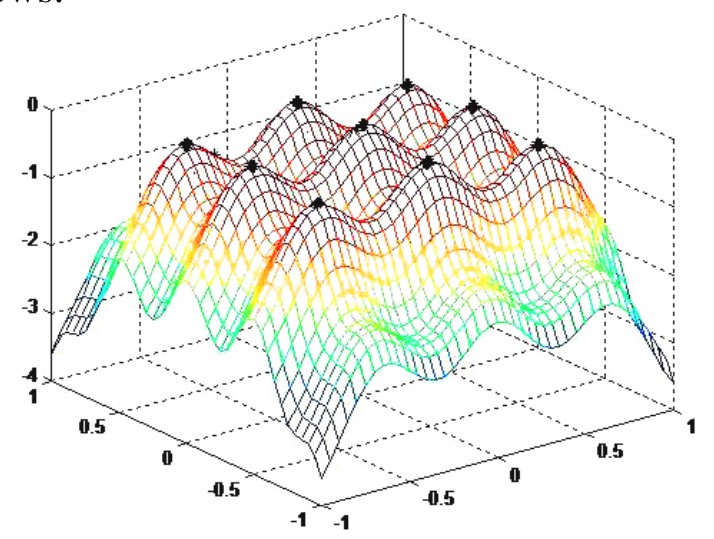

Fig.1 Intertextual text structure diagram

In the teaching of literary works, there are many intertextual texts that can be provided to teachers. They can be similar, and can be other works of the same author. How to choose and what to choose depends on how difficult the students are from their cognitive starting point to what they want to achieve. We should provide targeted intertextual texts. For example, if we study Hai Zi's poem 'Facing the sea, spring blossoms', if we read the poem alone, the direct feeling may be that the poet is writing happiness and yearning for happiness. This feeling is good, but it stays on the plane. If the teacher can provide students with some of Haizi's other poetry, especially the writing of dead poetry, such as: 'There was a kind of laughter in the dark night that laughed at the plank of my grave / you know, this is a land where the tigers are buried', we It will be a deeper understanding that life and death in the poet's heart are tightly intertwined.

\section{Summary}

Standing on the position of introducing the theory of narratology into the teaching of literary works, what we need to provide most is of course intertextual texts that can open eyes to students in the interpretation of textual forms. For example, when studying "Waiting for Godot," provide students with Mr. Lu Xun's "passing passengers," so that students can compare the recurring discourses, the different treatment methods of character descriptions, and the different reading experiences in the two texts. Students get a direct experience.

\section{References}

[1] Gabriela Tucan. The Reader's Mind Beyond the Text - The Science of Cognitive Narratology[J]. Romanian Journal of English Studies,2013,10(1).

[2] Michalis Kokonis. Intermediality between Games and Fiction: The "Ludology vs. Narratology" Debate in Computer Game Studies: A Response to Gonzalo Frasca[J]. Acta Universitatis Sapientiae, Film and Media Studies,2015,9(1).

[3] Shang Biwu. Unnatural narratology: core issues and critical debates[J]. Journal of Literary Semantics,2015,44(2).

[4] Jan Hanska. Narrative approach to the art of war and military studies - Narratology as military science research paradigm[J]. Journal of Military Studies,2014,5(1). 